\title{
Alergia a la proteína de la leche de vaca: enfoque diagnóstico y terapéutico
}

\section{Diagnostic and therapeutic approach to cow's milk protein allergy}

\author{
Ángela Mayerly Cubides-Munévar, MD, ${ }^{1}$ Alfredo Sadot Linero-Terán, MD, ${ }^{2}$ Mario Andrés Saldarriaga-Vélez, MD, ${ }^{3}$ \\ Erika Julieth Umaña-Bautista, MD, ${ }^{4}$ Eder Antonio Villamarín Betancourt, MD.${ }^{*}$
}

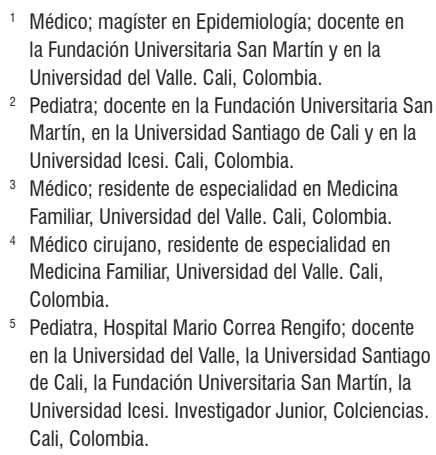

' Médico; magíster en Epidemiología; docente en la Fundación Universitaria San Martín y en la Universidad del Valle. Cali, Colombia.

2 Pediatra; docente en la Fundación Universitaria San Martín, en la Universidad Santiago de Cali y en la Universidad Icesi. Cali, Colombia.

3 Médico; residente de especialidad en Medicina Familiar, Universidad del Valle. Cali, Colombia. ${ }^{4}$ Médico cirujano, residente de especialidad en Medicina Familiar, Universidad del Valle. Cali, Colombia.

5 Pediatra, Hospital Mario Correa Rengifo; docente en la Universidad del Valle, la Universidad Santiago de Cali, la Fundación Universitaria San Martín, la Universidad Icesi. Investigador Junior, Colciencias. Cali, Colombia.

*Correspondencia: Eder Antonio Villamarín Betancourt, edervillamarin@gmail.com

Fecha recibido: $\quad 19 / 03 / 19$

Fecha aceptado: $06 / 08 / 19$

\begin{abstract}
Resumen
La prevalencia de la alergia a las proteínas de la leche de vaca (APLV) en el ámbito mundial es, aproximadamente, de 1,9 a 4,9\%. En Colombia, esta cifra se desconoce. En un alto porcentaje de los casos, no existe la sospecha por parte del personal de salud, y, por lo tanto, el diagnóstico y el tratamiento se retrasan. Esto acarrea un aumento en el tiempo y en los recursos que emplean los profesionales de la salud y los padres en procura de establecer la etiología del padecimiento de los niños que presentan esta enfermedad. Dentro de este contexto, la historia clínica es fundamental en la sospecha de la APLV, y es especialmente relevante la evaluación de antecedentes, en los cuales se destacan la presencia de la exposición temprana a la proteína, así como la atopia en familiares en primer grado de consanguinidad. La presentación de la APLV puede manifestarse con reacciones inmediatas a nivel digestivo (vómitos, diarrea aguda), cutáneo (urticaria, dermatitis, angioedema) y, con menos frecuencia, a partir de signos respiratorias y sistémicos. Sin embargo, la amplia variedad de manifestaciones clínicas y signos puede ser un reto para el profesional que no se encuentre sensibilizado con la patología, e incluso soslayar este diagnóstico retrasa la suspensión de la proteína de la leche de vaca de la dieta y demora el acceso a un tratamiento eficaz. El tratamiento ideal reconocido es la dieta de exclusión, la cual requiere un estricto cumplimiento. En los niños alimentados con lactancia materna exclusiva, será necesaria la dieta restrictiva de leche y sus derivados en la madre. En quienes no reciben lactancia, se deberá tratar mediante fórmulas de proteínas lácteas extensamente hidrolizadas (FEH) 0 a base de aminoácidos (FAA). Así bien, el pronóstico es favorable y la mayoría de niños tolerarán las proteínas de la leche de vaca a los 2 años, mientras que en pacientes con polisensibilización el proceso puede prolongarse. En el caso de no alcanzar la tolerancia, la inmunoterapia oral es una opción disponible.
\end{abstract}

\section{Palabras clave}

Alergia a la proteína de la leche de vaca, práctica clínica, guías, diagnóstico, tratamiento, prevención.

\begin{abstract}
The worldwide prevalence of cow's milk protein allergy (CMPA) is approximately $1.9 \%$ to $4.9 \%$. Its prevalence in Colombia is unknown. A high percentage of cases are unsuspected by medical personnel resulting in delayed diagnosis and treatment which increase the time and resources used to establish the etiology of this condition in children. The clinical history is fundamental for diagnosis of CMPA, especially the background evaluation. Of special importance are early exposure to the protein and atopy in first degree relatives. CMPA's initial presentation may be digestive, cutaneous or respiratory. Digestive symptoms can include vomiting and acute diarrhea, and cutaneous symptoms include hives, dermatitis and angioedema. Respiratory and systemic manifestations occur less frequently. The wide variety of clinical manifestations and signs can challenge health care professionals who are not alert to this pathology to the point that the diagnosis is not even considered event though delaying the suspension of cow's milk protein from the diet delays access to an effective treatment. The well-recognized ideal treatment is an exclusion diet which requires strict compliance. For children who are exclusively breastfed, the mother's diet must restrict milk and its derivatives. Children who are not breastfed, should be fed formulas of extensively hydrolyzed milk proteins based on amino acids. The prognosis is favorable, and most children will tolerate cow's milk proteins at two years. The process may take more years for polysensitive patients. Oral immunotherapy is an option that is available for patients who do not achieve toleration.
\end{abstract}

\section{Keywords}

Cow's milk protein allergy, clinical practice, guidelines, diagnosis, treatment, prevention. 


\section{INTRODUCCIÓN}

Las proteínas de la leche de vaca son los antígenos que con mayor frecuencia producen reacciones de hipersensibilidad en los lactantes, a través de la leche materna o por la ingestión directa de la fórmula. La alergia a la proteína de la leche de vaca (APLV) conduce a una gran variedad de manifestaciones clínicas, entre las que predomina el compromiso digestivo. Este puede presentarse por segmentos o en toda su extensión y es seguido en frecuencia por el compromiso de la piel y el respiratorio (1).

La alergia alimentaria puede ser mediada por anticuerpos de tipo inmunoglobulina $\mathrm{E}$ ( $\mathrm{IgE}$ ), no mediada por la IgE o mediada por mecanismos mixtos. Durante el primer año de vida, la APLV es la forma más frecuente de presentación de la alergia alimentaria y sus síntomas pueden ser inespecíficos: reflujo gastroesofágico (RGE) patológico, sangre en las deposiciones, inapetencia, dolor abdominal tipo cólico, diarrea, estreñimiento y, con menor frecuencia, se describen casos de enteropatía con alteraciones en el desarrollo ponderal $(1,2)$. Además de una menor ingesta de calcio y lípidos, en estos pacientes pediátricos también se ha observado una menor concentración sérica de retinol, betacaroteno, licopeno y 25-hidroxivitamina D (3).

El presente artículo es resultado de una revisión de la literatura y se usaron palabras claves como "cow's milk protein allergy", "clinical practice", "guidelines", "diagnosis", "treatment" y "prevention". Asimismo, las fuentes de los datos obtenidos fueron de Pubmed, para lo cual se realizó la búsqueda de artículos relevantes publicados en inglés y español, desde marzo de 2017 a junio de 2019.

Se incluyeron estudios clínicos aleatorizados, revisiones de literatura y publicaciones de casos. Los términos fueron desarrollados a partir de la ayuda de un especialista en epidemiología y un especialista pediatra.

Todos los títulos y resúmenes fueron recuperados de la publicación original para su selección y, posteriormente, se analizaron los artículos de forma independiente por dos revisores de la literatura. Se revisó un total de 95 artículos.

\section{DEFINICIÓN}

La APLV se define como una reacción adversa reproducible a una o más proteínas de la leche, usualmente caseínas, $\alpha$-lactoalbúmina, $\beta$-lactoglobulina, y mediada por uno o diversos mecanismos inmunes $(4,5)$. El mecanismo inmunológico que se presenta distingue la APLV de otras reacciones adversas a la leche de vaca, como la intolerancia a la lactosa.

\section{HISTORIA NATURAL}

Generalmente, los síntomas se desarrollan una semana después de la introducción de la leche de vaca, aunque pueden presentarse luego de 24 y 36 semanas $(6,7)$. La edad media de inicio es similar a $2,8+/-1,8$ meses y $3,5+/-2,8$ meses $(5,8)$.

En la mayoría de los niños, la APLV se manifiesta con síntomas anteriores a los 6 meses de edad, como se describe en múltiples revisiones de la literatura y en un estudio argentino realizado por Mehaudy y colaboradores (5-9). El desencadenante es la leche de vaca y las fórmulas o los alimentos a base de ella, posiblemente porque esta es la primera proteína alimentaria a la cual se exponen los niños. Una proporción menor de esta población puede desarrollar una reacción con la lactancia materna (10).

Estudios anteriores al 2005 mostraron que la APLV tenía un buen pronóstico, ya que se evidenció que entre un 80 y un $90 \%$ de los niños desarrollaron tolerancia durante la edad escolar (10-12).

\section{EPIDEMIOLOGÍA}

Aunque no existen datos epidemiológicos internacionales comparables sobre la prevalencia de la APLV, dado que hay diferentes métodos en la evaluación clínica, los resultados de los estudios de cohortes y los metaanálisis evidencian una prevalencia general del 1,9 al 4,9 \% de la APLV, con un pico de prevalencia (2-3\%) en el primer año de vida. En efecto, un estudio de Eggesbo y colaboradores describió una prevalencia $<1 \%$ en los niños mayores de 6 años en la población noruega (12).

Los padres reconocen la APLV en sus hijos con mucha más frecuencia de lo que puede ser confirmado mediante los estudios diagnósticos, y los síntomas que sugieren reacciones adversas a la proteína de la leche de vaca ocurren en el 5-15\% de los niños, lo cual excede las verdaderas aproximaciones de la prevalencia de la APLV (13).

El diagnóstico preciso es importante para evitar que los lactantes sean sometidos a dietas de exclusión inapropiadas, las cuales pueden tener un efecto sobre el crecimiento y el desarrollo a largo plazo. El pronóstico de esta entidad en la infancia es bueno y la tasa de remisión es de hasta el 85-90 \% a los 3 años, con un mejor pronóstico en los casos de síntomas gastrointestinales (14).

La mayoría de los niños presentan dos o más síntomas durante el cuadro clínico. Sin embargo, la presencia de una sola de estas manifestaciones no descarta la posibilidad de alergia. Es importante mencionar que los datos proceden de centros especializados en atención a alergias y trastornos gastrointestinales, lo que refleja incidencias tan elevadas 
como del $14 \%$ en consultas de primera vez, de las cuales el $71 \%$ corresponden a APLV (2).

\section{FISIOPATOLOGÍA}

La leche de vaca contiene cerca de 20 proteínas potencialmente sensibilizantes, que se encuentran en las fracciones de suero y caseína, e incluyen a-lactoalbúmina, $\beta$-lactoglobulina, inmunoglobulinas bovinas y alérgenos de caseína (15). El efecto del proceso industrial sobre las propiedades antigénicas/alergénicas de las proteínas de la leche de vaca es mínimo (16).

$\mathrm{Al}$ igual que con otras alergias alimentarias, la predisposición genética, las infecciones y la alteración de la microflora intestinal, así como la primera exposición, la dieta materna, la transmisión del antígeno a través de la leche materna, la cantidad y la frecuencia de la carga del antígeno son factores que promueven la tolerancia oral o la sensibilización a la leche de vaca (17).

Los órganos primarios de la alergia son el tracto gastrointestinal, la piel y el tracto respiratorio, y en algunos escenarios conduce a un compromiso sistémico. El antígeno, en este caso las proteínas de la leche de vaca, pasa a través del lumen intestinal y es reconocido por la célula $\mathrm{M}$ de la mucosa intestinal, la cual lleva la información a las células presentadoras de antígeno, que son usualmente las células dendríticas de la submucosa.

Así, las células presentadoras muestran el antígeno al linfocito $\mathrm{T}$ cooperador ( $\mathrm{T}$ helper $0 \mathrm{o}$ Th 0 ), el cual ocasiona una sobreexpresión de la respuesta de los linfocitos $\mathrm{T}$ cooperadores tipo 2 (Th2), mediante las citocinas que secreta, como las interleucinas (IL) 4 y 13 (18). Los Th2 estimulan los linfocitos B, que se preparan para sintetizar la IgE específica contra ese antígeno.

Por otro lado, en el caso de las expresiones clínicas no mediadas por la IgE, existen algunas citocinas, en particular la IL-5 y el factor de necrosis tumoral alfa (TNFa), secretadas por la célula Th0, las cuales promueven el reclutamiento de neutrófilos y la activación de eosinófilos y pueden determinar la aparición de edemas, dolor y funcionamiento anormal de los órganos. Así, cuando el niño es expuesto nuevamente al antígeno, se produce una reacción antígeno-anticuerpo que desencadena la respuesta de los linfocitos B previamente preparados, o la degranulación de los mastocitos/eosinófilos, lo cual genera manifestaciones en diferentes órganos (19).

\section{MANIFESTACIONES CLÍNICAS}

El inicio de los síntomas se presenta cuando existe una exposición al alérgeno (proteína de la leche de vaca), bien sea a causa del consumo de productos lácteos por parte de la madre que se encuentra lactando, por la ingesta de fórmulas infantiles o, directamente, por el consumo de leche de origen bovino. Según la severidad y el tiempo de la reacción, las manifestaciones clínicas pueden presentarse de tres maneras:

- Inmediatas: ocurren antes de 30 min y se caracterizan por la aparición de reacciones locales en la piel como urticaria, exantema (rash), síndrome alérgico oral, angioedema facial, anafilaxia y elevación de la IgE.

- Mediatas: se dan luego de unas horas y son ocasionadas por reacciones no mediadas por la IgE, generalmente con síntomas gastrointestinales.

- Tardías: se presentan entre el día 1 y 5, y la participación de la respuesta mediada por la IgE es incierta, caracterizada por síntomas gastrointestinales, respiratorios o cutáneos, como rinitis, eccema, urticaria, angioedema y anafilaxia, todos ellos asociados a la IgE, y la hemosiderosis pulmonar, la malabsorción con atrofia de vellosidades, la proctocolitis eosinofílica, la enterocolitis y la esofagitis, no asociados a la $\operatorname{IgE}(20)$.

Se estima que entre el 50 y el $60 \%$ de las manifestaciones clínicas son digestivas $(21,22)$ y la más frecuente es la deposición con sangre (5). Entre tanto, las manifestaciones respiratorias corresponden al 20 y $30 \%$, mientras que el $30-70 \%$ son manifestaciones cutáneas $(23,24)$. El más usual de estos signos en la piel es el exantema (25).

Además, pueden presentarse manifestaciones neurológicas y sistémicas como insomnio, edema y otras condiciones (26). De los síntomas gastrointestinales, tan solo una pequeña proporción es mediada por la IgE. La relación entre el RGE y la APLV se ha descrito en más del $50 \%$ de los casos, cuyas evidencias conducen a que las dos entidades pueden coexistir.

Vandenplas y colaboradores reportaron una prevalencia de enfermedad por RGE, diagnosticada con $\mathrm{pH}$-metría, en el $50 \%$ de los niños con APLV, frente a un $10 \%$ de niños sanos $(26,27)$ (Tabla 1).

\section{DIAGNÓSTICO}

Las características no específicas de las manifestaciones clínicas son la causa de que no exista un reconocimiento temprano de la enfermedad. La leche de vaca, de una forma u otra, es ingerida diariamente por los lactantes en cantidades superiores a las de cualquier otro alimento individual. Es importante describir la edad de inicio, el tipo de síntomas y su frecuencia, así como el tiempo entre la ingestión y el inicio de los síntomas, los detalles del tipo de alimentación y los antecedentes de atopia personal y familiar (26).

Es necesario, en caso de alimentación con lactancia materna, definir si la madre se encuentra consumiendo 
Tabla 1. Manifestaciones clínicas de la APLV, ordenadas por el sistema de órganos y el tipo de reacción inmune.

\begin{tabular}{|c|c|}
\hline $\begin{array}{l}\text { Manifestaciones } \\
\text { gastrointestinales } \\
(50-60 \%)\end{array}$ & $\begin{array}{l}\text { Síndrome de alergia oral. } \\
\text { Edema labial. }\end{array}$ \\
\hline $\begin{array}{l}\text { Alergia gastrointestinal } \\
\text { inmediata }\end{array}$ & $\begin{array}{l}\text { Vómitos. } \\
\text { Diarrea. }\end{array}$ \\
\hline $\begin{array}{l}\text { Reacciones } \\
\text { respiratorias mediadas } \\
\text { por } \operatorname{lgE}(20-30 \%)\end{array}$ & $\begin{array}{l}\text { Rinitis. } \\
\text { Asma. }\end{array}$ \\
\hline $\begin{array}{l}\text { Reacciones cutáneas } \\
\text { mediadas por } \operatorname{lgE} \\
(30-70 \%)\end{array}$ & $\begin{array}{l}\text { Urticaria. } \\
\text { Dermatitis alérgica de contacto. } \\
\text { Erupción eccematosa generalizada. }\end{array}$ \\
\hline $\begin{array}{l}\text { Reacciones de } \\
\text { aparición tardía }\end{array}$ & $\begin{array}{l}\text { Dermatitis atópica. } \\
\text { Enfermedad de reflujo gastroesofágico. } \\
\text { Esofagitis eosinofílica alérgica. } \\
\text { Síndrome de enterocolitis inducida por } \\
\text { proteínas alimentarias. } \\
\text { Enteropatía por proteína de leche de vaca. } \\
\text { Estreñimiento. } \\
\text { Irritabilidad severa (cólico). } \\
\text { Gastroenteritis. } \\
\text { Enfermedad pulmonar crónica inducida por } \\
\text { la leche. } \\
\text { Síndrome de Heiner. }\end{array}$ \\
\hline Choque anafiláctico & \\
\hline
\end{tabular}

IgE: inmunoglobulina E. Modificada de la referencia 26

lácteos y sus derivados, dado el paso que pueden tener las proteínas de la leche de la vaca a la leche materna, con la posterior exposición al desarrollo de la APLV.

Asimismo, se debe establecer si el niño alimentado con lactancia materna exclusiva fue expuesto durante las $24 \mathrm{~h}$ posteriores del nacimiento a la suplementación con fórmulas sucedáneas de la leche materna, como en casos de prevención de hipoglicemia o protocolos institucionales de atención del neonato. Se ha observado que dicha práctica en estos niños se relaciona con un riesgo 7 veces mayor de sufrir de APLV que en sus controles de alimentación realizados durante las primeras $24 \mathrm{~h}$ con lactancia materna (27).

Ninguna de las pruebas de diagnóstico disponibles en situaciones clínicas rutinarias demuestra o excluye completamente la APLV (26). Los médicos pueden realizar una prueba de punción (skin prick test) y de determinación de la IgE específica, así como pruebas de parches. Sin embargo, estas solo indican la sensibilización al sustrato, lo cual no constituye necesariamente la confirmación de una reacción alérgica.

Algunos estudios han mostrado que la sensibilidad y la especificidad de la prueba de punción es del 31,8 y el 90,3\%, respectivamente, con un valor predictivo negativo (VPN)
$>95 \%$ y un valor predictivo positivo (VPP) $<50 \%$. Esto sirve para descartar reacciones de anticuerpos específicos y para el diagnóstico etiológico de asma, rinitis y alergia a los alimentos (28). En los casos en que no se puede ejecutar un reto alimenticio es posible utilizar tanto la prueba cutánea como la $\operatorname{IgE}(29,30)$.

\section{PROCEDIMIENTOS DE DETECCIÓN DIAGNÓSTICA}

El desafío doble ciego controlado con placebo es considerado el método de referencia en el diagnóstico de la APLV, pero en la práctica solo se realiza un desafío abierto (31). El paciente con sospecha de APLV deberá seguir una dieta de exclusión durante 2 a 4 semanas; los lactantes alimentados con fórmula iniciarán una fórmula extensamente hidrolizada (FEH), y las madres que proporcionan lactancia materna exclusiva implementarán una dieta libre de las proteínas de leche de vaca. Así, si la APLV está presente, las manifestaciones clínicas desaparecerán.

La proteína de la leche de vaca se reintroduce progresivamente y a partir de entonces los síntomas clínicos son monitorizados. El riesgo de un desafío abierto es una sobreestimación del diagnóstico (32). Un desafío doble ciego controlado con placebo cegará al padre y al médico en cuanto a la introducción de la proteína de la leche de vaca y es la única medida objetiva para hacer el diagnóstico.

Infortunadamente, este proceso es costoso, requiere de una preparación extensa, consume mucho tiempo y es difícil de realizar. La supervisión médica durante un desafío es necesaria porque la severidad de los síntomas no puede predecirse. Cuando las pruebas de alergia adicionales (IgE específica del suero, prueba cutánea) son negativas, las manifestaciones que amenazan la vida son extremadamente raras, pero en pacientes con antecedentes de reacciones graves o altos niveles de $\mathrm{IgE}$ se indica una atención hospitalaria con un protocolo establecido.

En los escenarios en los cuales se confirma la APLV debe mantenerse una dieta de eliminación hasta que el paciente esté en una edad entre los 9-12 meses, o por lo menos durante 6 meses. Luego de ello, al realizar un nuevo desafío, los niños que no desarrollan manifestaciones relacionadas con la alergia, y hasta una semana después, pueden reanudar su dieta normal.

La prueba intraepidérmica y la medición de la IgE específica permiten establecer la sensibilización del niño a la proteína de la leche de vaca y predecir una posible nueva reacción. La probabilidad de un resultado positivo en la prueba de reto oral controlado es $>95 \%$, cuando se tiene una concentración de IgE específica en menores de 2 años $>\mathrm{UI} / \mathrm{mL}$ y de $15 \mathrm{UI} / \mathrm{mL}$ en mayores de 2 años (33). Con la prueba intraepidérmica, el VPP de una reacción al consumo de leche es $>95 \%$, cuando se forma un habón de 6 
$\mathrm{mm}$ en menores de 2 años y de $8 \mathrm{~mm}$ en mayores de esta edad (34) (Tabla 2).

- Pruebas no mediadas por la IgE: pueden ser no invasivas, como la prueba del parche atópico. Esto permite evaluar la respuesta celular, pero sus valores no están estandarizados. También existen otras pruebas como la función celular, las precipitinas, la permeabilidad intestinal, los eosinófilos y del TNF $\alpha$. Entre tanto, las invasivas con endoscopia digestiva para la toma de biopsias requieren un estudio histológico, pero no se recomiendan usualmente.

- Histología: a nivel del intestino delgado, el patólogo debe reportar más de 60 eosinófilos en 6 campos de alto poder, o más de 15 a 20 eosinófilos por campo, con más del $25 \%$ de infiltrado inflamatorio, y la presencia de eosinófilos intraepiteliales más abscesos eosinofílicos en las criptas.

En el colon, se debe encontrar macroscópicamente un eritema focal, una mucosa friable, una hiperplasia folicular linfoide ( $75 \%$ de los casos) y vasculitis alérgica; a nivel microscópico, es necesario hallar el infiltrado local de eosinófilos en todos los compartimentos (33).

\section{HERRAMIENTAS DE DIAGNÓSTICO}

Los síntomas y signos de la APLV tienen una presentación amplia e inespecífica, lo que puede retrasar un correcto diagnóstico. Dicho diagnóstico implica una dieta de eliminación de 2 a 4 semanas, seguida por el desafío de la exposición nuevamente a la proteína de la leche de vaca.
Por tanto, ha sido elaborado un recurso clínico para facilitar la identificación y el proceso de diagnóstico.

Se trata de la puntuación de síntomas relacionados con la leche de vaca (Cow's Milk-related Symptom Score, CoMiSS) (38), la cual incluye manifestaciones gastrointestinales (regurgitación, alteración de las heces), signos cutáneos (eccema, urticaria), síntomas del tracto respiratorio y síntomas generales como el tiempo de llanto.

El CoMiSS varía de 0 a 33 puntos, los cuales van desde la ausencia de síntomas y signos a múltiples manifestaciones con gravedad de presentación de estos. Se propuso un valor de corte $\geq 12$ como recomendación del panel de expertos. Los datos existentes muestran que el valor predictivo de la herramienta para identificar a los bebés con riesgo de APLV puede ser del $80 \%$.

Así, el CoMiSS fue validado en un estudio que encontró una sensibilidad del 87,5 \% y una especificidad del 78,6\% (39). Esta herramienta se convierte en un paso a la reducción de retrasos y dificultades de diagnóstico de la APLV (38) (Figura 1).

\section{DIAGNÓSTICO DIFERENCIAL}

La lista de posibles diagnósticos diferenciales para la APLV incluye infecciones víricas repetitivas e intolerancia transitoria a la lactosa. Por otro lado, el RGE se ha mencionado como una posible manifestación de la $\operatorname{APLV}(40,41)$. Asimismo, la APLV también se ha relacionado con cólicos del lactante y contribuye en alrededor del $10 \%$ de los niños que sufren este síntoma $(42,43)$.

Tabla 2. Procedimientos de detección diagnóstica

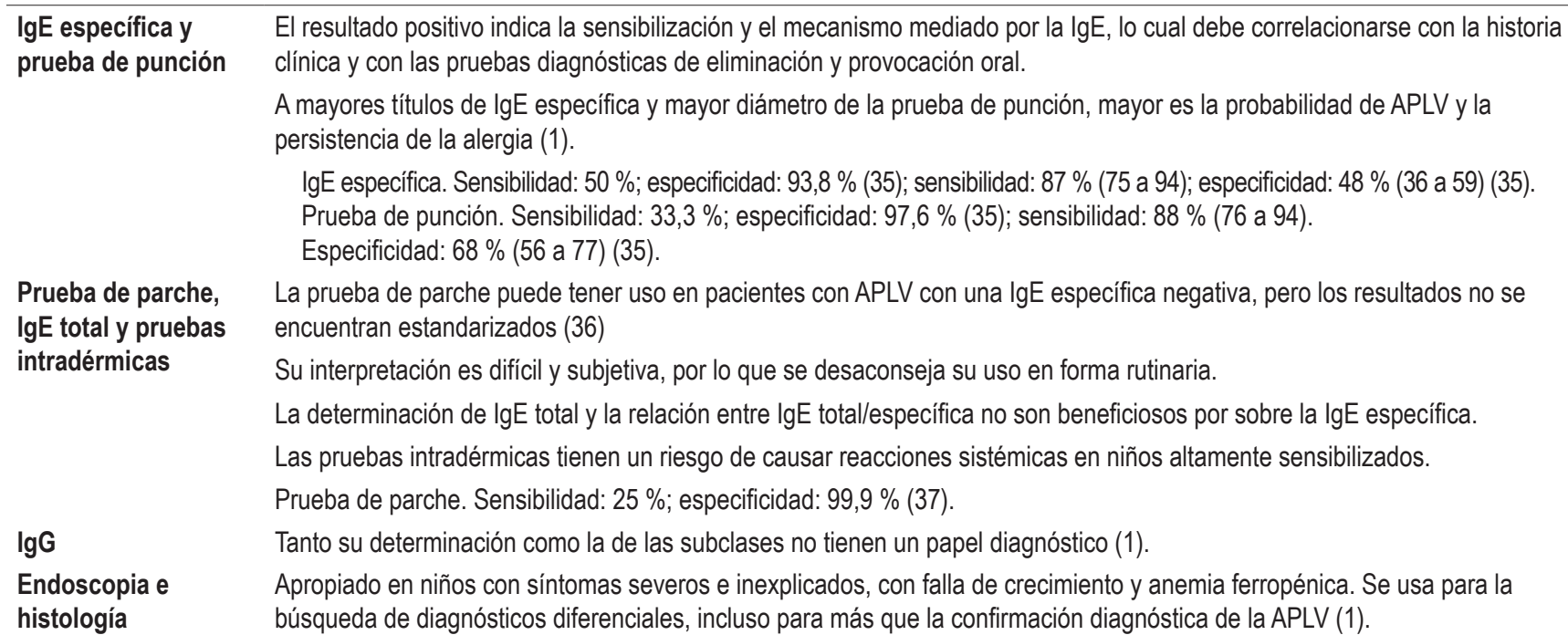

El resultado positivo indica la sensibilización y el mecanismo mediado por la lgE, lo cual debe correlacionarse con la historia clínica y con las pruebas diagnósticas de eliminación y provocación oral.

A mayores títulos de lgE específica y mayor diámetro de la prueba de punción, mayor es la probabilidad de APLV y la persistencia de la alergia (1).

IgE específica. Sensibilidad: 50 \%; especificidad: 93,8 \% (35); sensibilidad: 87 \% (75 a 94); especificidad: 48 \% (36 a 59) (35). Prueba de punción. Sensibilidad: 33,3\%; especificidad: 97,6 \% (35); sensibilidad: 88 \% (76 a 94).

Especificidad: 68 \% (56 a 77) (35).

La prueba de parche puede tener uso en pacientes con APLV con una IgE específica negativa, pero los resultados no se encuentran estandarizados (36)

Su interpretación es difícil y subjetiva, por lo que se desaconseja su uso en forma rutinaria.

La determinación de lgE total y la relación entre lgE total/específica no son beneficiosos por sobre la IgE específica. Las pruebas intradérmicas tienen un riesgo de causar reacciones sistémicas en niños altamente sensibilizados.

Prueba de parche. Sensibilidad: $25 \%$; especificidad: 99,9\% (37).

Tanto su determinación como la de las subclases no tienen un papel diagnóstico (1).

Apropiado en niños con síntomas severos e inexplicados, con falla de crecimiento y anemia ferropénica. Se usa para la búsqueda de diagnósticos diferenciales, incluso para más que la confirmación diagnóstica de la APLV (1).

IgE: inmunoglobulina E; IgG: inmunoglobulina G; APLV: alergia a las proteínas de la leche de vaca 


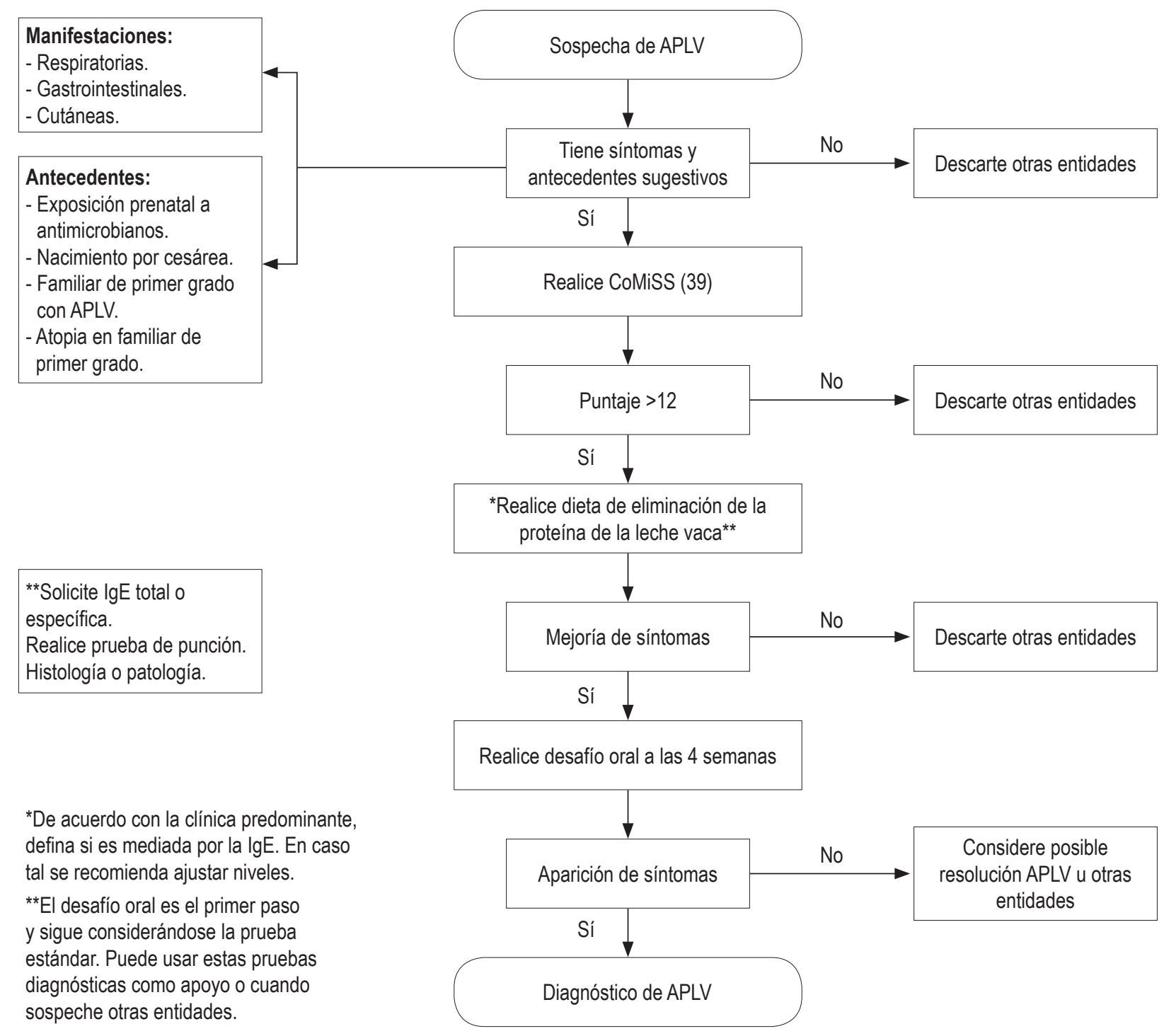

Figura 1. Flujograma diagnóstico de la APLV. IgE: inmunoglobulina E; APLV: alergia a las proteínas de la leche de vaca; CoMiSS: puntuación de síntomas relacionados con la leche de vaca (Cow's Milk-related Symptom Score)

Aunque en algunos lactantes se sugiere una correlación entre la dermatitis atópica y la APLV, muchos casos de este tipo de dermatitis no están asociados a la presencia de la alergia. A menor edad del lactante, o cuanto más severa sea la dermatitis atópica, más fuerte parece ser la asociación (44).

Las reacciones a otros alimentos (especialmente el huevo y la soya, el trigo, el pescado) ocurren frecuentemente en combinación con la APLV (45). Por tanto, estos alimentos deben evitarse cuando se esté realizando una prueba de exclusión diagnóstica.

\section{TRATAMIENTO DE LA APLV}

La estrategia más segura para el tratamiento de la APLV es evitar estrictamente la proteína de la leche de vaca. La decisión de utilizar una fórmula sustituta y elegir la mejor opción para satisfacer las necesidades nutricionales de los niños con APLV debe hacerse, sobre todo, en función de la edad del paciente y la historia de otras alergias alimentarias. Para los lactantes que reciben lactancia materna exclusiva, el diagnóstico de eliminación implica la exclusión de los 
derivados lácteos de la dieta materna. Las madres necesitan recibir suplementos de calcio y asesoría dietética, a fin de evitar deficiencias nutricionales (1).

La fórmula a base de la leche de vaca, y cualquier alimento complementario que contenga sus derivados, deben evitarse en lactantes con lactancia materna exclusiva. Cuando los síntomas de alergia ocurren en lactantes alimentados con fórmula, ya sea exclusivamente o como suplemento a la lactancia materna, se les debe suministrar una fórmula terapéutica que haya demostrado reducir clínicamente la alergenicidad y tenga alta tolerabilidad $(46,47)$. Las FEH y las fórmulas basadas en aminoácidos (FAA) son las dos alternativas recomendadas para la alimentación con fórmula entre los lactantes con $\operatorname{APLV}(25,46,48,49)$.

Las FEH están indicadas en el tratamiento y en la prevención de la APLV y son toleradas por la mayoría de los lactantes y niños con esta condición $(1,48)$. Entre tanto, las FAA se desarrollan para superar la hipersensibilidad contra las proteínas residuales en la FEH, particularmente en casos con enteropatía grave o con múltiples alergias alimentarias (48). Por esta razón, las FAA pueden considerarse solo en lactantes con reacciones graves como anafilaxia, enteropatía, esofagitis eosinofílica, enterocolitis inducida por proteínas, junto con casos en los cuales existe un compromiso a nivel de múltiples sistemas, diferentes alergias alimentarias e intolerancia a las FEH $(14,48,50)$.

Mientras que las fórmulas de soya se asocian con una menor alergenicidad que las basadas en leche de vaca (51, 52 ), se han planteado preocupaciones por su alto contenido de isoflavonas (fitoestrógenos) (53).

La Sociedad Europea de Gastroenterología Pediátrica, Hepatología y Nutrición (The European Society for Paediatric Gastroenterology, Hepatology and Nutrition, ESPGHAN) y la Academia Americana de Pediatría (American Academy of Pediatrics, AAP) consideran el uso de las FEH y las FAA para el tratamiento de lactantes con APLV como la primera opción (52-54). Asimismo, no recomiendan el uso de fórmulas parcialmente hidrolizadas (FPH) basadas en proteína de la leche de vaca, ni derivados lácteos de otros mamíferos (55-57). Pese a ello, los países adscritos a Medio Oriente decidieron en un consenso incluir en su algoritmo de manejo el uso de las FPH como terapia puente entre las FEH y las FAA, en casos seleccionados.

En lactantes con APLV documentada, y nutridos exclusivamente con leche materna y fórmula, los alimentos de transición deben estar libres de proteínas de leche de vaca hasta que el desarrollo de la tolerancia se confirme mediante pruebas de exposición oral. En los niños con APLV que están en tratamiento con dieta de exclusión, más allá de los primeros 12 meses de edad, se recomienda la supervisión dietética realizada por un profesional de la salud especializado o capacitado en nutrición pediátrica, a fin de decidir sobre las cantidades suficientes de nutrientes, proteínas, calcio, vitamina $\mathrm{D}$ y vitamina $\mathrm{A}$ en la dieta. Esto también es fundamental para establecer la necesidad de una fórmula nutricional o los suplementos para lograr un crecimiento normal según la edad $(49,56,57)$.

De igual forma, es primordial determinar la tolerancia a la proteína de la leche de vaca, a fin de evitar prolongar dietas restrictivas que afectan el crecimiento y el desarrollo del niño, y que, por otra parte, puedan comprometer el estado nutricional de la madre que está lactando $(2,49)$.

\section{NIÑOS ALIMENTADOS CON LACTANCIA MATERNA EXCLUSIVA}

Durante la alimentación con lactancia materna exclusiva, se eliminará de la dieta de la madre todo alimento que contenga proteína láctea. Es necesario indicar a la mujer la restricción de alimentos que contengan en sus rótulos información nutricional denominadas leche, suero de leche, sólidos de leche, caseína y caseinato.

$\mathrm{Al}$ cumplirse 6 meses, el proceso de introducción de alimentación complementaria deberá realizarse retrasando el consumo de comidas con contenido de proteína de leche de vaca. Durante el tiempo de la dieta de eliminación de la madre, ella debe recibir asesoría nutricional, suplementación de 1000 mg de calcio al día y vitamina D 800 UI al día (50).

\section{NIÑOS ALIMENTADOS CON FÓRMULA 0 ALIMENTACIÓN MIXTA}

Estos pacientes deben recibir una dieta con exclusión de productos lácteos asociada a una fórmula terapéutica para APLV:

\section{Fórmulas indicadas en APLV}

Las fórmulas que se encuentran indicadas en la APLV son aquellas que no generan una reacción en el $90 \%$ de los lactantes y niños con APLV confirmada.

- FAA: son fórmulas sintéticas a base de aminoácidos libres. Estas se hallan libres de lactosa y constituyen la mejor opción para el tratamiento de la APLV, por lo que se consideran la primera línea.

- FEH: son fórmulas adaptadas para uso en lactantes, las cuales constan de procesos de hidrólisis enzimática, tratamiento térmico y ultrafiltración. Esto facilita que dicha proteína se forme por péptidos de cadenas más cortas.

- Fórmulas de aminoácidos con suplementación de oligosacáridos de la leche materna: son fórmulas que se encuentran en desarrollo, en las cuales se plantea la suplementación de una FEH con 2'fucosil-lactosa (2'FL) y lacto-N-neotetraosa (LNnT). Estos dos suplementos 
tienen su fundamento de uso en los oligosacáridos propios de la leche materna y con su adición podrían reducir el riesgo de infección entérica. Además, proporcionarían un sustrato para la colonización del intestino del niño con bifidobacterias benéficas y reducirían la colonización por agentes patógenos.

Asimismo, la presencia de estos suplementos afecta de forma positiva la integridad epitelial intestinal, la apoptosis y la permeabilidad intestinal. En efecto, en modelos animales, han mostrado una reducción de los síntomas alérgicos a la proteína de la leche de vaca, pero este es un campo aún por explorar $(2,58)$.

\section{Fórmulas inadecuadas en APLV}

- FPH: son fórmulas en las cuales los péptidos conservan epítopos de péptidos, capaces de producir reacciones alérgicas (49).

- Leches de otros mamíferos: estas no son nutricionalmente apropiadas para el uso en los lactantes (49).

- Leche de almendras, avellanas, arroz, soya, coco y otros vegetales: el jugo de estas mal llamadas leches no es nutricionalmente adecuado, ya que no proviene de la extracción de una glándula mamaria. Además, brinda un bajo aporte calórico y una baja biodisponibilidad (49).

- Fórmulas de soya: la diferencia entre las fórmulas de soya y las mal llamadas leches de otros vegetales radica en que las primeras son adaptadas para el uso de lactantes. Por su contenido de fitatos, es posible que la disponibilidad de minerales como el zinc, el hierro, el magnesio y el fosforo sea menor. Además, se han reportado reacciones cruzadas en un 10 a $30 \%$ de los casos con APLV (49).

De igual forma, se han obtenido casos de reacción cruzada con las fórmulas nutricionales infantiles a base de soya en el 17,3\% de los lactantes con APLV, independientemente de si fueron positivos o negativos en IgE específica para la proteína de la leche de vaca $(52,59)$.

En particular, los lactantes con múltiples alergias alimentarias y enterocolitis eosinofílica también reaccionan a la proteína de soya (60). Por lo tanto, los grupos de especialistas tienen diferentes posturas sobre el uso de la fórmula de soya para la APLV, pero generalmente no se recomienda su implementación antes de los 6 meses de edad $(46,52,58)$.

\section{PREVENCIÓN DE LA APLV}

El riesgo de alergia tiene un componente genético y puede determinarse por un factor familiar. Datos históricos muestran que la incidencia de la enfermedad atópica es de alre- dedor del $15 \%$. Sin embargo, esta se incrementa en niños con antecedentes familiares de enfermedad atópica. Así, si dentro de una familia un niño presenta una alergia, el riesgo de que también ocurra en los hermanos es 10 veces mayor que en la población general (61).

La lactancia materna es universalmente reconocida como la mejor manera de proporcionar alimento ideal para el crecimiento y el desarrollo saludable de los lactantes. La Organización Mundial de la Salud recomienda que los lactantes sean amamantados exclusivamente durante los primeros 6 meses de vida para lograr este crecimiento y desarrollo saludables. Después de este período, los niños deben recibir alimentos complementarios nutricionalmente adecuados y seguros, mientras que la lactancia continúa hasta los 2 años o más. La lactancia materna exclusiva ha demostrado ser el mejor método para prevenir la alergia.

Se ha identificado que los niños alimentados con lactancia materna exclusiva presentan un menor riesgo de desarrollar APLV. También se ha observado que si la APLV aparece durante la infancia es menos severa en comparación con el uso de fórmulas o alimentación mixtas. La razón de este menor riesgo es que la leche materna posee 100000 veces menos proteínas que la leche de vaca y, además, contiene inmunomoduladores (50).

Con respecto a la dieta infantil, existen pruebas contradictorias sobre el efecto preventivo de retrasar la introducción de alimentos sólidos en la incidencia de la alergia. Algunos estudios sugieren que el tipo de restricción y el retraso en el momento de la introducción de los alimentos pueden prevenir la alergia (62-64). En contraste, otros autores plantean que la introducción temprana no tiene ningún efecto adverso e incluso puede ser protectora contra la alergia $(64,65)$.

Asimismo, la restricción de los alimentos sólidos más allá de los 6 meses de edad puede conducir a una ingesta inadecuada de nutrientes, problemas de alimentación y déficit en el crecimiento (65). En síntesis, la evidencia sugiere que no existe un beneficio al retrasar la introducción o imponer una restricción específica de alimentos potencialmente alergénicos más allá de 4-6 meses (2).

Entre tanto, los prebióticos y los probióticos suelen comercializarse con la promesa de que pueden ayudar en la prevención de la alergia $(66,67)$. En efecto, existen estudios que sugieren que la suplementación probiótica de las madres durante el embarazo y la lactancia puede contribuir en la prevención de la enfermedad atópica temprana en los lactantes (68).

Una revisión sistemática encontró una mayor tasa de adquisición de tolerancia a la proteína de la leche de vaca al final de los 3 años, en niños que habían recibido probióticos, en comparación con placebo. No obstante, el nivel de evidencia es bajo, dada la calidad de los estudios incluidos (69). 
También hay evidencia que sugiere que la suplementación de $\mathrm{FEH}$ con prebióticos puede disminuir la incidencia de manifestaciones alérgicas como la dermatitis atópica, las sibilancias recurrentes y la urticaria alérgica en la infancia $(70,71)$. Sin embargo, aún no se han publicado estudios que demuestren si esto también ocurre con las FPH suplementadas con prebióticos.

De cualquier forma, estos datos sugieren que los prebióticos y los probióticos son seguros y que, si bien existe alguna evidencia de que pueden reducir la incidencia de alergia, se necesitan más pruebas para que puedan convertirse en una recomendación de rutina.

Otra propuesta en la modulación de la APLV es la aplicación de tratamientos térmicos a la leche de la vaca, lo cual podría inducir cambios en la estructura de la proteína. Sin embargo, estos estudios aún no son contundentes y sus resultados hasta el momento son in vitro. Por tanto, no es recomendable ofrecer lácteos hervidos, horneados o expuestos a cocción por largos períodos, pues no ofrecen ningún beneficio demostrado en la tolerancia a la proteína de la leche de vaca $(72,73)$ (Figura 2).

\section{CONCLUSIONES}

La APLV puede presentarse en los lactantes que reciben lactancia materna exclusiva y en los niños alimentados con fórmula. Las manifestaciones no son patognomónicas y una historia clínica completa con un examen exhaustivo son la base del diagnóstico. La confirmación mediante una prueba de punción, una $\operatorname{IgE}$ específica en suero o una prueba del parche atópico carecen de especificidad, mientras que el reto alimenticio doble ciego controlado con placebo sigue siendo el tratamiento de referencia (14).

El debate sobre el manejo de la APLV se prolongará según las manifestaciones clínicas predominantes y el contexto del paciente. Entre tanto, las FEH basadas en la leche de vaca siguen siendo la opción terapéutica recomendada y preferida, mientras que las FAA están reservadas para los casos más graves. Asimismo, la lactancia materna se constituye en la mejor opción -y también en la más económica- para alimentar a los niños sanos y a aquellos con APLV.

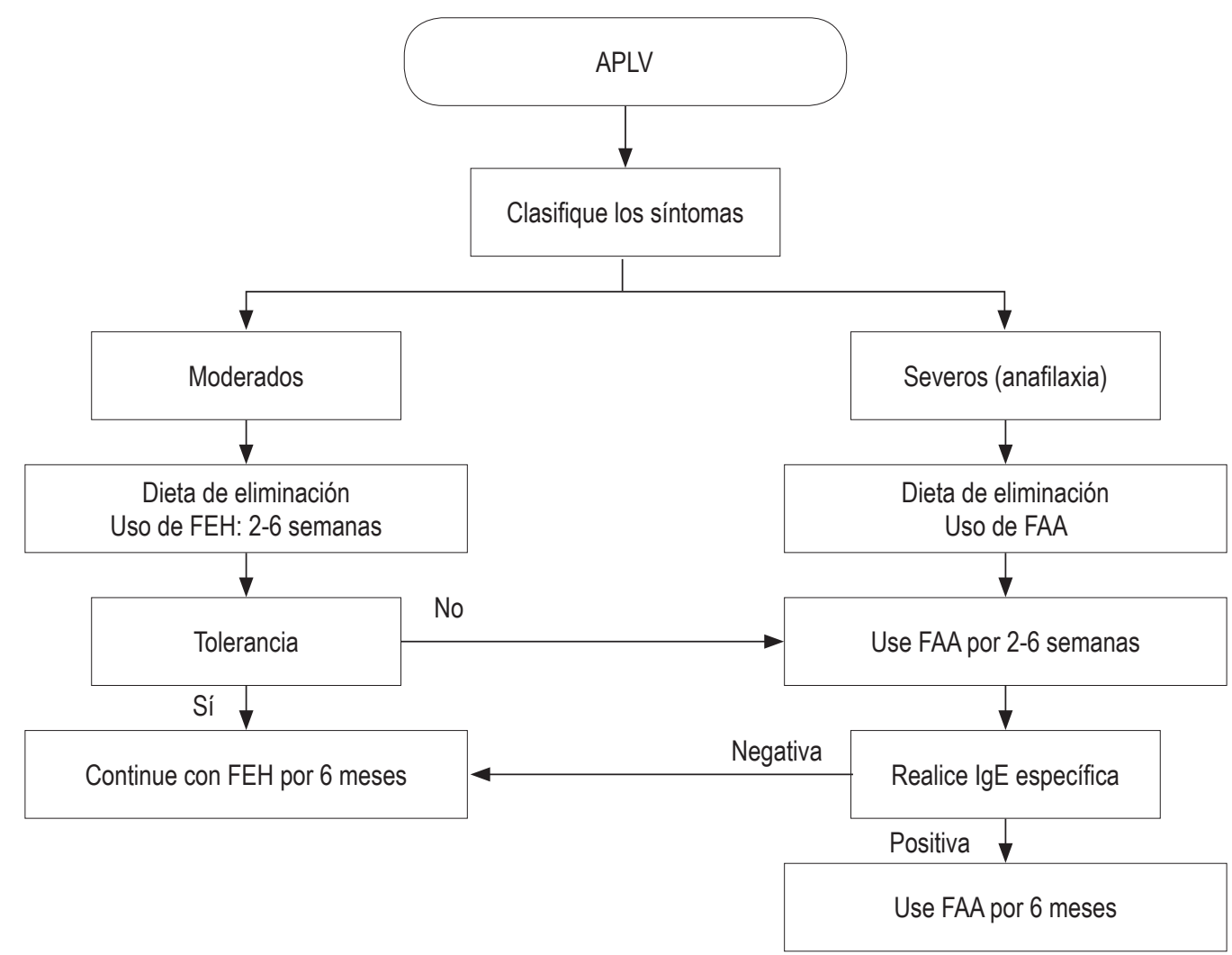

Figura 2. Flujograma para el tratamiento de la APLV. APLV: alergia a la proteína de la leche de vaca; FEH: fórmula extensamente hidrolizada; FAA: fórmula a base de aminoácidos; IgE: inmunoglobulina E. Modificada de la referencia 2. 


\section{REFERENCIAS}

1. Koletzko S, Niggemann B, Arato A, Dias JA, Heuschkel $\mathrm{R}$, Husby $\mathrm{S}$, et al. Diagnostic approach and management of cow's-milk protein allergy in infants and children: ESPGHAN GI Committee practical guidelines. J Pediatr Gastroenterol Nutr. 2012;55(2):221-9. https://doi. org/10.1097/MPG.0b013e31825c9482

2. Vandenplas Y, Abuabat A, Al-Hammadi S, Aly GS, Miqdady MS, Shaaban SY, et al. Middle East Consensus Statement on the Prevention, Diagnosis, and Management of Cow's Milk Protein Allergy. Pediatr Gastroenterol Hepatol Nutr. 2014;17(2):6173. http://dx.doi.org/10.5223/pghn.2014.17.2.61

3. Boaventura RM, Mendonça RB, Fonseca FA, Mallozi M, Souza FS, Sarni ROS. Nutritional status and food intake of children with cow's milk allergy. Allergol Immunopathol (Madr).2019;47(6):544-550.http://dx.doi.org/10.1016/j. aller.2019.03.003

4. Hill DJ, Firer MA, Shelton MJ, Hosking CS. Manifestations of milk allergy in infancy: clinical and immunologic findings. J Pediatr. 1986;109(2):270-6. https://doi.org/10.1016/ S0022-3476(86)80384-5

5. Mehaudy R, Parisi C, Petriz N, Eymann A, Jauregui MB, Orsi M. Prevalence of cow's milk protein allergy among children in a university community hospital. Arch Argent Pediatr. 2018;116(3):219-223. https://doi.org/10.5546/ aap.2018.219

6. Høst A, Halken S. A prospective study of cow milk allergy in Danish infants during the first 3 years of life. Clinical course in relation to clinical and immunological type of hypersensitivity reaction. Allergy. 1990;45(8):587-96. https://doi. org/10.1111/j.1398-9995.1990.tb00944.x

7. Jakobsson I, Lindberg T. A prospective study of cow's milk protein intolerance in Swedish infants. Acta Paediatr Scand. 1979;68(6):853-9. https://doi. org/10.1111/j.1651-2227.1979.tb08223.x

8. Santos A, Dias A, Pinheiro JA. Predictive factors for the persistence of cow's milk allergy. Pediatr Allergy Immunol. 2010;21(8):1127-34. https://doi.org/10.1111/j.13993038.2010.01040.x

9. Kvenshagen B, Halvorsen R, Jacobsen M. Adverse reactions to milk in infants. Acta Paediatr. 2008;97(2):196-200. https://doi.org/10.1111/j.1651-2227.2007.00599.x

10. Bishop JM, Hill DJ, Hosking CS. Natural history of cow milk allergy: clinical outcome. J Pediatr. 1990;116(6):8627. https://doi.org/10.1016/S0022-3476(05)80641-9

11. Høst A, Halken S, Jacobsen HP, Christensen AE, Herskind AM, Plesner K. Clinical course of cow's milk protein allergy/ intolerance and atopic diseases in childhood. Pediatr Allergy Immunol. 2002;13(s15):23-8. https://doi.org/10.1034/ j.1399-3038.13.s.15.7.x

12. Vanto T, Helppilä S, Juntunen-Backman K, Kalimo K, Klemola T, Korpela R, Koskinen P. Prediction of the development of tolerance to milk in children withcow's milk hypersensitivity. J Pediatr. 2004;144(2):218-22. https:// doi.org/10.1016/j.jpeds.2003.10.063
13. Høst A. Frequency of cow's milk allergy in childhood. Ann Allergy Asthma Immunol. 2002;89(6 Suppl 1):33-7. https://doi.org/10.1016/S1081-1206(10)62120-5

14. De Greef E, Hauser B, Devreker T, Veereman-Wauters G, Vandenplas Y. Diagnosis and management of cow's milk protein allergy in infants. World J Pediatr. 2012;8(1):19-24. https://doi.org/10.1007/s12519-012-0332-x

15. Wal JM. Cow's milk proteins/allergens. Ann Allergy Asthma Immunol. 2002;89(6 Suppl 1):3-10. https://doi. org/10.1016/S1081-1206(10)62115-1

16. Nowak-Wegrzyn A, Fiocchi A. Rare, medium, or well done? The effect of heating and food matrix on food protein allergenicity. Curr Opin Allergy Clin Immunol. 2009;9(3):2347. https://doi.org/10.1097/ACI.0b013e32832b88e7

17. Karlsson MR, Rugtveil J, Brandtzaeg P. Allergen-responsive CD41CD251 regulatory cells in children who have outgrown cow's milk allergy. J. Exp. Med. 2004; 199: 16791688. https://doi.org/10.1084/jem.20032121

18. Salvatore S, Vandenplas Y. Gastroesophageal reflux and cow milk allergy: is there a link? Pediatrics. $2002 ; 110(5): 972-84$. https://doi.org/10.1542/peds.110.5.972

19. Daza W, Dadán S, Rojas AM. Alergia alimentaria en la infancia. Programa de Educación Continuada (Precop), Soc Col de Pediat. 2014;13(3):49-58.

20. Magazzù G, Scoglio R. Gastrointestinal manifestations of cow's milk allergy.Ann Allergy Asthma Immunol. 2002;89(6 Suppl 1):65-8. https://doi.org/10.1016/S10811206(10)62126-6

21. Sicherer SH. Determinants of systemic manifestations of food allergy. J Allergy Clin Immunol. 2000;106(5 Suppl):S251-7. https://doi.org/10.1067/mai.2000.110158

22. Walker-Smith J. Cow's milk allergy: a new understanding from immunology. Ann Allergy Asthma Immunol. 2003;90(6 Suppl 3):81-3. https://doi.org/10.1016/S10811206(10)61666-3

23. Huang J, Walker WA. Food allergic enteropathy. En: Huang J, Walker WA. Review of pediatric gastroenterology disease and nutrition. Hamilton: BC Decker Inc; 2005. p. 145-146.

24. Nosan G, Jakic M, Jager M, Paro-Panjan D. Prognostic accuracy of clinical signs and diagnostic tests in cow's milk allergy in newborns. Pediatr Neonatol. 2017;58(5):449454. https://doi.org/10.1016/j.pedneo.2016.09.009

25. Bahna SL. Clinical expressions of food allergy. Ann Allergy Asthma Immunol. 2003;90(6 Suppl 3):41-4. https://doi. org/10.1016/S1081-1206(10)61659-6

26. Fiocchi A, Schünemann HJ, Brozek J, Restani P, Beyer $\mathrm{K}$, Troncone R, et al. Diagnosis and Rationale for Action Against Cow's Milk Allergy (DRACMA): a summary report. J Allergy Clin Immunol. 2010;126(6):1119-28.e12. https://doi.org/10.1016/j.jaci.2010.10.011

27. Kelly E, DunnGalvin G, Murphy BP, O’B Hourihane J. Formula supplementation remains a risk for cow's milk allergy in breast-fed infants. Pediatr Allergy Immunol. 2019;30(8):810-816. https://doi.org/10.1111/pai.13108

28. Vanto T, Juntunen-Backman K, Kalimo K, Klemola T, Koivikko A, Koskinen P, et al. The patch test, skin prick test, 
and serum milk-specific IgE as diagnostic tools in cow's milk allergy in infants. Allergy. 1999;54(8):837-42. https://doi. org/10.1034/j.1398-9995.1999.00134.x

29. Costa AJ, Sarinho ES, Motta ME, Gomes PN, de Oliveira de Melo SM, da Silva GA. Allergy to cow's milk proteins: what contribution does hypersensitivity in skin tests have to this diagnosis? Pediatr Allergy Immunol. 2011;22(1 Pt 2):e1338. https://doi.org/10.1111/j.1399-3038.2010.00988.x

30. García-Ara MC, Boyano-Martínez MT, Díaz-Pena JM, Martín-Muñoz MF, Martín-Esteban M. Cow's milk-specific immunoglobulin $\mathrm{E}$ levels as predictors of clinical reactivity in the follow-up of the cow's milk allergy infants. Clin Exp Allergy. 2004;34(6):866-70. https://doi.org/10.1111/ j.1365-2222.2004.01976.x

31. Vandenplas Y, Koletzko S, Isolauri E, Hill D, Oranje AP, Brueton $\mathrm{M}$, et al. Guidelines for the diagnosis and management of cow's milk protein allergy in infants. Arch Dis Child. 2007;92(10):902-8. https://doi.org/10.1136/ adc.2006.110999

32. Venter C, Pereira B, Voigt K, Grundy J, Clayton CB, Gant $\mathrm{C}$, et al. Comparison of open and double-blind placebo-controlled food challenges in diagnosis of food hypersensitivity amongst children. J Hum Nutr Diet. 2007;20(6):565-79. https://doi.org/10.1111/j.1365-277X.2007.00828.x

33. Sampson HA. Utility of food-specific IgE concentrations in predicting symptomatic food allergy. J Allergy Clin Immunol. 2001;107(5):891-6. https://doi.org/10.1067/ mai.2001.114708

34. Nowak-Wegrzyn A, Bloom KA, Sicherer SH, Shreffler WG, Noone S, Wanich N, et al. Tolerance to extensively heated milk in children with cow's milk allergy. J Allergy Clin Immunol. 2008;122(2):342-7, 347.e1-2. https://doi. org/10.1016/j.jaci.2008.05.043

35. Lifschitz C, Szajewska H. Cow's milk allergy: evidencebased diagnosis and management for the practitioner. Eur J Pediatr. 2015;174(2):141-150. https://doi.org/10.1007/ s00431-014-2422-3

36. Cuomo B, Indirli GC, Bianchi A, Arasi S, Caimmi D, Dondi $A$, et al. Specific IgE and skin prick tests to diagnose allergy to fresh and baked cow's milk according to age: a systematic review. Ital J Pediatr. 2017;43(1):93. https://doi. org/10.1186/s13052-017-0410-8

37. Čelakovská J, Krcmova I, Bukac J, Vaneckova J. Sensitivity and specificity of specific IgE, skin prick test and atopy patch test in examination of food allergy. 2016;28(2):238-247. http://dx.doi.org/10.1080/09540105.2016.1258548

38. Vandenplas Y, Dupont C, Eigenmann P, Host A, Kuitunen M, Ribes-Koninckx C, et al. A workshop report on the development of the Cow >s Milk-related Symptom Score awareness tool for young children. Acta Paediatr. 2015;104(4):334-9. https://doi.org/10.1111/apa.12902

39. Zeng Y,ZhangJ, Dong G, Liu P, Xiao F, LiW, et al. Assessment of Cow>s milk-related symptom scores in early identification of cow $>$ s milk protein allergy in Chinese infants. BMC Pediatr. 2019;19(1):191. https://doi.org/10.1186/ s12887-019-1563-y
40. Vandenplas Y, Mukherjee R, Dupont C, Eigenmann P, Høst A, Kuitunen $\mathrm{M}$, et al. Protocol for the validation of sensitivity and specificity of the Cow $>$ sMilk-related Symptom Score (CoMiSS) against open food challenge in a single-blinded, prospective, multicentre trial in infants. BMJ Open. 2018;8(5):e019968. https://doi.org/10.1136/bmjopen-2017-019968

41. Xanthakos SA, Schwimmer JB, Melin-Aldana H, Rothenberg ME, Witte DP, Cohen MB. Prevalence and outcome of allergic colitis in healthy infants with rectal bleeding: a prospective cohort study.J Pediatr Gastroenterol Nutr. 2005;41(1):16-22. https://doi.org/10.1097/01.MPG.0000161039.96200.F1

42. Hill DJ, Heine RG, Cameron DJ, Catto-Smith AG, Chow CW, Francis DE, et al. Role of food protein intolerance in infants with persistent distress attributed to reflux esophagitis. J Pediatr. 2000;136(5):641-7. https://doi.org/10.1067/ mpd.2000.104774

43. Jakobsson I, Lindberg T. Cow $>$ s milk proteins cause infantile colic in breast-fed infants: a double-blind crossover study. Pediatrics. 1983;71(2):268-71.

44. Isolauri E, Tahvanainen A, Peltola T, Arvola T. Breastfeeding of allergic infants. J Pediatr. 1999;134(1):27-32. https://doi.org/10.1016/S0022-3476(99)70368-9

45. Saarinen UM, Kajosaari M. Breastfeeding as prophylaxis against atopic disease: prospective follow-up study until 17 years old. Lancet. 1995;346(8982):1065-9. https://doi. org/10.1016/S0140-6736(95)91742-X

46. American Academy of Pediatrics. Committee on Nutrition. Hypoallergenic infant formulas. Pediatrics. 2000;106(2 Pt 1):346-9. https://doi.org/10.1542/peds.106.2.346

47. Giampietro PG, Kjellman NI, Oldaeus G, Wouters-Wesseling W, Businco L. Hypoallergenicity of an extensively hydrolyzed whey formula. Pediatr Allergy Immunol. 2001;12(2):83-6. https://doi.org/10.1034/j.1399-3038.2001.012002083.x

48. Vandenplas Y, De Greef E, Devreker T. Treatment of Cow $>$ s Milk Protein Allergy. Pediatr Gastroenterol Hepatol Nutr. 2014;17(1):1-5. http://dx.doi.org/10.5223/pghn.2014.17.1.1

49. Isolauri E, Sütas Y, Mäkinen-Kiljunen S, Oja SS, Isosomppi R, Turjanmaa K. Efficacy and safety of hydrolyzed cow milk and amino acid-derived formulas in infants with cow milk allergy. J Pediatr. 1995;127(4):550-7. https://doi. org/10.1016/S0022-3476(95)70111-7

50. Cordero C, Prado F, Bravo P. Actualización en manejo de alergia a la proteína de leche de vaca: fórmulas lácteas disponibles y otros brebajes. 2018;89(3):310-317. https://doi. org/10.4067/S0370-41062018005000503

51. Halpern SR, Sellars WA, Johnson RB, Anderson DW, Saperstein S, Reisch JS. Development of childhood allergy in infants fed breast, soy, or cow milk.J Allergy Clin Immunol. 1973;51(3):13951.https://doi.org/10.1016/0091-6749(73)90019-5

52. Bhatia J, Greer F; American Academy of Pediatrics Committee on Nutrition. Use of soy protein-based formulas in infant feeding. Pediatrics. 2008;121(5):1062-8. https:// doi.org/10.1542/peds.2008-0564

53. Vandenplas Y, Castrellon PG, Rivas R, Gutiérrez CJ, Garcia LD, Jimenez JE, et al. Safety of soya-based infant formulas 
in children. Br J Nutr. 2014;111(8):1340-60. https://doi. org/10.1017/S0007114513003942

54. ESPGHAN Committee on Nutrition, Agostoni C, Axelsson I, Goulet O, Koletzko B, Michaelsen KF, et al. Soy protein infant formulae and follow-on formulae: a commentary by the ESPGHAN Committee on Nutrition. J Pediatr Gastroenterol Nutr. 2006;42(4):352-61. https://doi. org/10.1097/01.mpg.0000189358.38427.cd

55. Høst A, Koletzko B, Dreborg S, Muraro A, Wahn U, Aggett $\mathrm{P}$, et al. Dietary products used in infants for treatment and prevention of food allergy. Joint Statement of the European Society for Paediatric Allergology and Clinical Immunology (ESPACI) Committee on Hypoallergenic Formulas and the European Society for Paediatric Gastroenterology, Hepatology and Nutrition (ESPGHAN) Committee on Nutrition. Arch Dis Child. 1999;81(1):80-4. https://doi. org/10.1136/adc.81.1.80

56. Järvinen KM, Chatchatee P. Mammalian milk allergy: clinical suspicion, cross-reactivities and diagnosis. Curr Opin Allergy Clin Immunol. 2009;9(3):251-8. https://doi. org/10.1097/ACI.0b013e32832b3f33

57. Laitinen K, Kalliomäki M, Poussa T, Lagström H, Isolauri E. Evaluation of diet and growth in children with and without atopic eczema: follow-up study from birth to 4 years. $\mathrm{Br}$ J Nutr. 2005;94(4):565-74. https://doi.org/10.1079/ BJN20051503

58. Nowak-Wegrzyn A, Czerkies L, Reyes K, Collins B, Heine RG. Confirmed Hypoallergenicity of a Novel Whey-Based Extensively Hydrolyzed Infant Formula Containing Two Human Milk Oligosaccharides. Nutrients. 2019;11(7). pii: E1447. https://doi.org/10.3390/nu11071447

59. Dupont C, Chouraqui JP, Linglart A, Bocquet A, Darmaun D, Feillet F, et al. Nutritional management of cow's milk allergy in children: An update. Arch Pediatr. 2018;25(3):236-243. https://doi.org/10.1016/j.arcped.2018.01.007

60. Klemola T, Vanto T, Juntunen-Backman K, Kalimo K, Korpela R, Varjonen E. Allergy to soy formula and to extensively hydrolyzed whey formula in infants with cow's milk allergy: a prospective, randomized study with a follow-up to the age of 2 years. J Pediatr. 2002;140(2):219-24. https:// doi.org/10.1067/mpd.2002.121935

61. Nowak-Wegrzyn A, Sampson HA, Wood RA, Sicherer SH. Food protein-induced enterocolitis syndrome caused by solid food proteins. Pediatrics. 2003;111(4 Pt 1):829-35. https://doi.org/10.1542/peds.111.4.829

62. American College of Allergy, Asthma, \& Immunology. Food allergy: a practice parameter. Ann Allergy Asthma Immunol. 2006;96(3 Suppl 2):S1-68.
63. Fergusson DM, Horwood LJ, Shannon FT. Early solid feeding and recurrent childhood eczema: a 10-year longitudinal study. Pediatrics. 1990;86(4):541-6.

64. Morgan J, Williams P, Norris F, Williams CM, Larkin M, Hampton S. Eczema and early solid feeding in preterm infants. Arch Dis Child. 2004;89(4):309-314. https://doi. org/10.1136/adc.2002.020065

65. Zutavern A, Brockow I, Schaaf B, Bolte G, von Berg A, Diez $\mathrm{U}$, et al. Timing of solid food introduction in relation to atopic dermatitis and atopic sensitization: results from a prospective birth cohort study. Pediatrics. 2006;117(2):401-11. https://doi.org/10.1542/peds.2004-2521

66. Koplin JJ, Osborne NJ, Wake M, Martin PE, Gurrin LC, Robinson $\mathrm{MN}$, et al. Can early introduction of egg prevent egg allergy in infants? A population-based study. J Allergy Clin Immunol. 2010;126(4):807-13. https://doi. org/10.1016/j.jaci.2010.07.028

67. Boyce JA, Assa'ad A, Burks AW, Jones SM, Sampson HA, Wood RA, et al. Guidelines for the diagnosis and management of food allergy in the United States: summary of the NIAIDsponsored expert panel report. Nutr Res. 2011;31(1):61-75. https://doi.org/10.1016/j.jaci.2010.10.008

68. Osborn DA, Sinn JK. Prebiotics in infants for prevention of allergy. Cochrane Database Syst Rev. 2013;(3):CD006474. https://doi.org/10.1002/14651858.CD006474.pub3

69. Qamer S, Deshmukh M, Patole S. Probiotics for cow's milk protein allergy: a systematic review of randomized controlled trials. Eur J Pediatr. 2019;178(8):1139-1149. https:// doi.org/10.1007/s00431-019-03397-6

70. Kalliomäki M, Salminen S, Poussa T, Arvilommi H, Isolauri E. Probiotics and prevention of atopic disease: 4-year follow-up of a randomised placebo-controlled trial. Lancet. 2003;361(9372):1869-71. https://doi.org/10.1016/S01406736(03)13490-3

71. Arslanoglu S, Moro GE, Schmitt J, Tandoi L, Rizzardi S, Boehm G. Early dietary intervention with a mixture of prebiotic oligosaccharides reduces the incidence of allergic manifestations and infections during the first two years of life. J Nutr. 2008;138(6):1091-5. https://doi.org/10.1093/ jn/138.6.1091

72. Bavaro SL, De Angelis E, Barni S, Pilolli R, Mori F, Novembre EM, et al. Modulation of Milk Allergenicity by Baking Milk in Foods: A Proteomic Investigation. Nutrients. 2019; 11(7). pii: E1536. https://doi.org/10.3390/nu11071536

73. Chen M, Sutherland A, Birrueta G, Laubach S, Leonard S, Peters B, et al. Analysis of Allergen-Specific T Cell and IgE Reactivity to Different Preparations of Cow's MilkContaining Food Extracts. Cells. 2019;8(7):667. https:// doi.org/10.3390/cells8070667 